[CONTRIBUtion FROM THE ChEMICAL LABORATORY OF HARVARd UNIVERSity.]

\title{
STUDIES IN THE CYCLOPROPANE SERIES. VI.
}

\author{
By E. P. KOHLER AND W. N. JONES.
}

Received May 17, 1919.

In the last paper of this series ${ }^{1}$ the properties of a cyclopropane ketonic acid were compared with those of a closely related cyclopropane diacid. We now present the facts obtained while studying the corresponding diketone. The relation between these substances is shown by the following formulas:
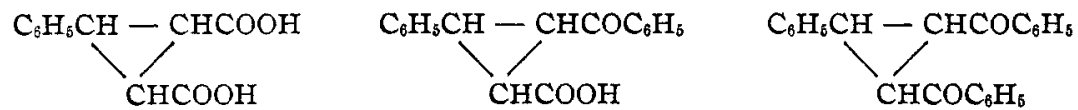

The diketone was obtained by brominating benzylidene diacetophenone and eliminating hydrogen bromide from the product. This reaction might give one of three substances depending on the way in which hydrogen bromide is eliminated: I. A cyclopropane derivative if the hydrogen and bromine come from the $\alpha-\gamma$ positions.

$\mathrm{C}_{6} \mathrm{H}_{5} \mathrm{CH}-\mathrm{CHCOC}_{6} \mathrm{H}_{5}$

II. An ethylenic compound if they are removed from adjoining atoms, $\mathrm{C}_{6} \mathrm{H}_{5} \mathrm{C}=\mathrm{CHCOC}_{6} \mathrm{H}_{5}$

$\mathrm{CH}_{2} \mathrm{COC}_{6} \mathrm{H}_{5}$

is from an enolic modification,
III. A dihydrofurane derivative if the elimination $\mathrm{C}_{6} \mathrm{H}_{6} \mathrm{CH}-\mathrm{CHCOC}_{6} \mathrm{H}_{6}$

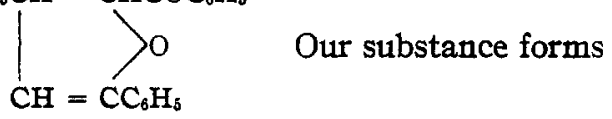

a dioxime, therefore it is not the furane derivative. With hydrogen bromide in glacial acetic acid it gives a bromofurane which has a chain different from that of the ethylenic diketone, and which could be formed only from the cyclopropane derivative

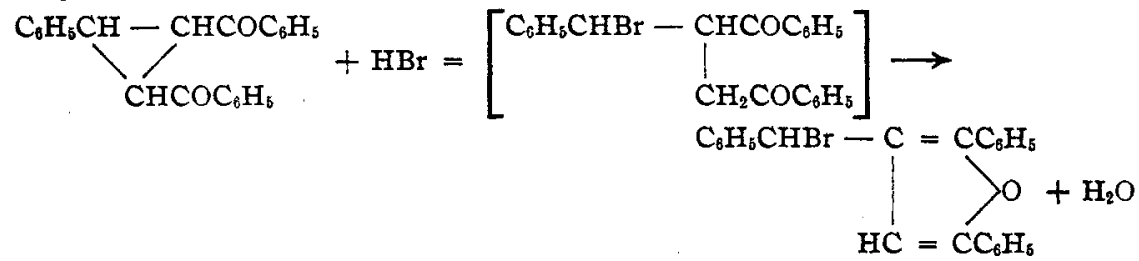

The cyclopropane derivative may also be made by introducing two bromine atoms into benzylidene diacetophenone and digesting the product with potassium iodide.

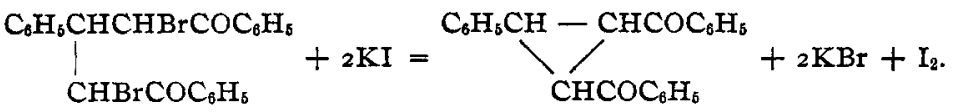

This method is somewhat more laborious than the former, but admira-

1 This Journal, 4I, IO93 (I9I9). 
bly shows the ease with which the ring is closed. The product is stereoisomeric with that obtained from the monobromo compound.

Phenyldibenzoyl-cyclopropane is a 1,4-diketone as well as a cyclopropane derivative. It gives a dioxime with hydroxylamine and ditertiary alcohols with organic magnesium compounds, but does not show the tendency to form furane derivatives which is characteristic of 1,4-diketones. Its most conspicuous chemical property is that of combining with most of the substances which can be added to $\alpha, \beta$ unsaturated ketones. With nascent hydrogen, hydrobromic acid, free bromine and phosphorus pentachloride it gives products similar to those obtained from ethylenic compounds. It does not, however, reduce permanganate or sive $\mathrm{r}, 4$ addition products with organic magnesium compounds.

The substance combines with hydrogen more readily than any other cyclopropane derivative that we have studied. Half an hour's boiling with alcohol and zinc dust suffices to reduce it completely to benzylidene diacetophenone, the ring opening at the point at which it had been closed.

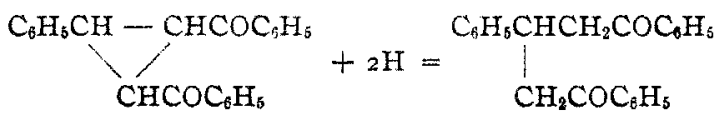

The cyclopropane derivative does not, like the corresponding ketonic acid, combine with halogen acids in alcoholic solution. In glacial acetic acid, however, it combines rapidly with hydrobromic acid. The ring is opened between carbon atoms 2 and 3 , and the addition product immediately loses water, thus forming a furane derivative.

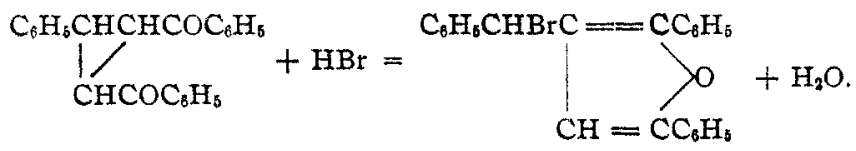

The resulting furane derivative, like most of the addition products obtained in this work, is only remotely related to known substances, hence a number of transformations were necessary to determine its structure. This was finally established by relating it to 1,5 -diphenyl furane. The successive steps are shown by the following formulas:

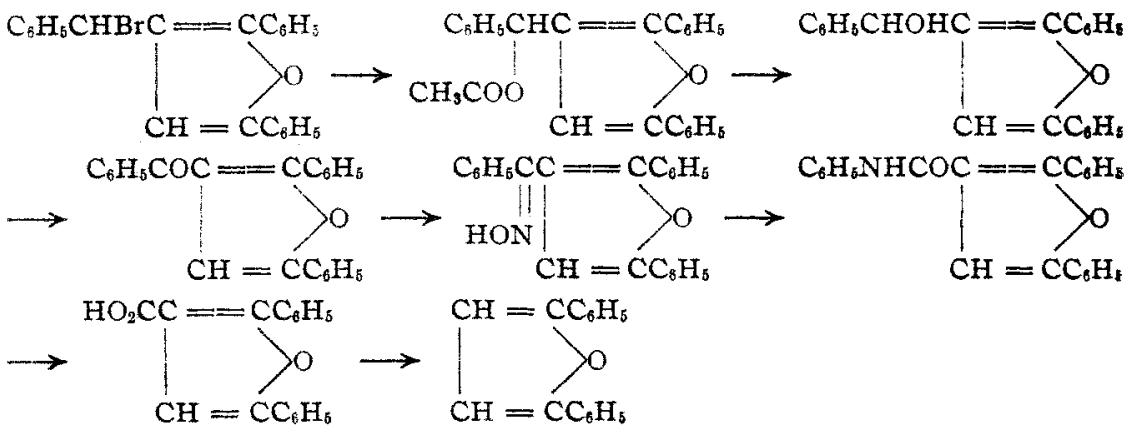


The cyclopropane derivative acts smoothly with phosphorus pentachloride under the conditions that have been found most favorable for the corresponding reaction with unsaturated ketones. The products to be anticipated are represented by the following formulas, of which the first represents the compound that would be expected if the ring is not involved, and the others the substances that might be formed by a reaction like that which Straus ${ }^{1}$ obtained with benzal-acetophenone.

(I).<smiles>CCCCC(C(=O)Nc1ccccc1)C(Cl)C(Cl)(Cl)Cl</smiles>

(II).<smiles>CCOC(=O)C(C=C(Cl)Cl)C(Cc1ccccc1)C(F)(Cl)c1ccccc1</smiles>

(III)

$\mathrm{C}_{6} \mathrm{H}_{5} \mathrm{CHC}=\mathrm{CClC}_{6} \mathrm{H}_{5}$

Only one product was obtained. For this the first formula could be discarded at once, for the substance has nothing in common with ketochlorides of this type; it is not affected by water nor by prolonged boiling with alcohol.

Each of the remaining formulas represents a dichloro compound, containing one active, and one inactive chlorine. In agreement with this the substance readily loses one molecule of hydrogen chloride when boiled with excess of potassium acetate. The possible formulas for the new sub. stances are,

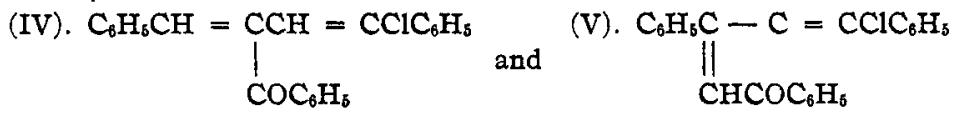

It is not at all easy to distinguish between these two formulas. Each of them represents an $\alpha, \beta$-unsaturated ketone, a halogen compound with an unreactive halogen, and a butadiene derivative which on oxidation with permanganate would in all probability give only potassium benzoate and potassium chloride. As the most promising way out of the difficulty we decided to treat the substance with phenyl magnesium bromide. A reaction between an unsaturated ketone such as is represented by Formula IV, and any organic magnesium compound should consist in $I, 4$ addition to the conjugated system, the final product being a more saturated ketone. The ketone represented by Formula V, on the other hand should give a tertiary alcohol because the two substituents in the $\beta$ position hinder $I, 4$ addition to the conjugated system. The substance in question gave an excellent yield of ketone. The cyclopropane derivative therefore reacts with phosphorus pentachloride exactly like an $\alpha, \beta$ unsaturated ketone, the ring taking the place of an ethylene linkage.

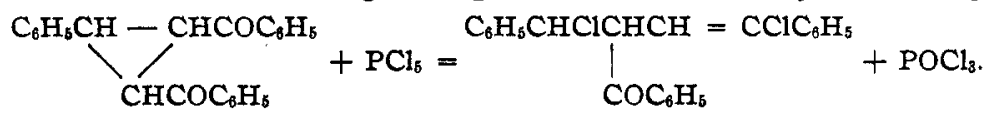

The product obtained by adding bromine to the cyclopropane derivative presented the most difficult problem of all and we have not as yet found a completely satisfactory solution. The only possible formulas are:

\footnotetext{
${ }^{1}$ Ann., 394, 290 (1912).
} 

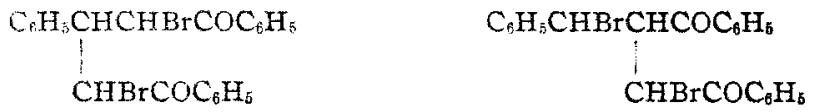

The first represents the dibromo compound used in one of the methods of preparation of the cyclopropane derivative. With potassium acetate it gives either a bromocyclopropane derivative or the corresponding acetate, depending upon the amount of acetate used.

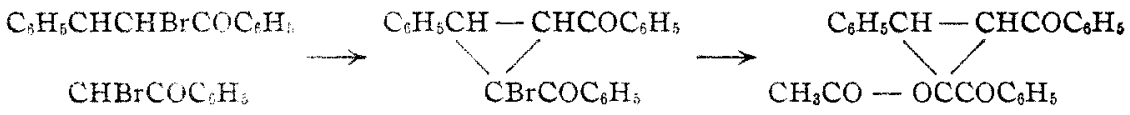

The new dibromo compound gives the same cyclopropane derivative with potassium iodide or zinc, and as it also gives the same products with potassium acetate the two substances therefore may be stereoisomers. On the other hand a substance such as is represented by Formula II could very well give the same products, and as we never obtained both substances in the same reaction, nor were able to transform either into the other, stereoisomerism seems improbable.

The bromo compound obtained by the action of potassium acetate on the dibromide is one of the very few known cyclopropane derivatives which have bromine in combination with a carbon atom of the ring. All efforts to remove another molecule of hydrogen bromide and thus get a cyclopropene derivative were unsuccessful. The bromine is easily replaceable, but it is not possible to get the corresponding hydroxyl compound either by hydrolysis of the bromine derivative with bases or the corresponding acetate with acids.

Evidently the hydroxyl compound rapidly undergoes a rearrangement similar to that which has balked all previous attempts to get hydroxy cyclopropanes. With alkalies the bromo compound gave only yellow oils, which appeared to be diketones, while hydrolysis of the acetate with alcoholic hydrochloric acid gave a furane derivative.

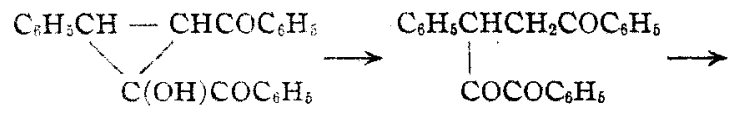

Experimental Part.

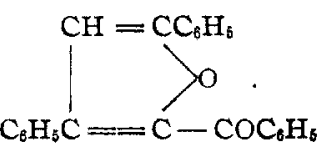

The benzal-diacetophenone with which we started was made according to the directions given by Kostanecki. ${ }^{2}$ The average yield of pure product was $50 \%$. The diketone reacts with bromine a little above the ordinary temperature, giving either a monobromo or a dibromo substitution product. The result depends largely upon the amount of bromine used; but both of the bromine compounds are sensitive substances which in contact with solutions containing hydrobromic acid change into uncrystallizable gums that materially decrease the yield. 
$\alpha, \gamma, \epsilon$-Triphenyl- $\beta$-bromo-pentanedione- $\alpha, \epsilon,: \mathrm{C}_{6} \mathrm{H}_{5} \mathrm{COCHBrCH}\left(\mathrm{C}_{6} \mathrm{H}_{5}\right)$ $\mathrm{CH}_{2} \mathrm{COC}_{6} \mathrm{H}_{5}$. - To a warm solution of $50 \mathrm{~g}$. of benzaldiacetophenone in $50 \mathrm{cc}$. of chloroform, $8.3 \mathrm{cc}$. of bromine was added while the flask was cooled with tap water. The chloroform was immediately evaporated under reduced pressure, great care being taken to avoid heating the residue. The greenish yellow paste that remained was dissolved in boiling alcohol and deposited a colorless solid, which was purified by recrystallization from the same solvent. The yield of pure product was $46 \%$.

Calc. for $\mathrm{C}_{23} \mathrm{H}_{18} \mathrm{BrO}_{2}: \mathrm{Br}$, 19.6. Found: 19.7 .

The monobromo compound melts with decomposition at $13 \mathrm{I}^{\circ}$. It is almost insoluble in ether and ligroin, moderately in boiling alcohol and benzene, and very soluble in chloroform.

$\alpha, \gamma, \epsilon$-Triphenyl- $\beta, \delta$-dibromo-pentanedione- $\alpha, \epsilon, \quad \mathrm{C}_{6} \mathrm{H}_{5} \mathrm{COCHBr}\left(\mathrm{C}_{6} \mathrm{H}_{5}\right)$ $\mathrm{CHBrCOC}_{6} \mathrm{H}_{5}$. - The dibromo compound was made exactly like the monobromo compound except that twice as much bromine was used with the same amount of ketone. The solvent was allowed to evaporate spontaneously and the residue recrystallized from alcohol.

The yield of pure product was $69 \%$. Since some of this substance is formed whenever the diketone is brominated it was found advantageous to combine the preparation of the mono- and dibromo compounds. For this purpose $8 \mathrm{cc}$. of bromine was added gradually to a solution of $50 \mathrm{~g}$. of the diketone in $50 \mathrm{cc}$. of chloroform. The cooled solution was inoculated with the monobromo compound and allowed to stand for several hours, during which time the mono derivative separated. This was filtered off and the filtrate treated with $2 \mathrm{cc}$. of bromine. The dibromo compound crystallized from the solution. The yield by this method was $47.5 \mathrm{~g}$. of mono- and $12.5 \mathrm{~g}$. of dibromo derivative. The dibromo compound melts with decomposition at $149^{\circ}$. It is very sparingly soluble in ether and ligroin, moderately in boiling alcohol, readily in benzene and chloroform.

Calc. for $\mathrm{C}_{23} \mathrm{H}_{19} \mathrm{O}_{2} \cdot \mathrm{Br}_{2}: \mathrm{Br}, 32.8$. Found: 32.9 .

I,2-Dibenzoyl-3-phenyl-cyclopropane, $\mathrm{C}_{6} \mathrm{H}_{5} \mathrm{CH}-\mathrm{CHCOC}_{6} \mathrm{H}_{5},-\mathrm{A}$ num$\mathrm{CHCOC}_{6} \mathrm{H}_{5}$

ber of reagents eliminated hydrogen bromide from the monobromo compound; as all of them gave the same product and since this was insensitive to alkalies, we generally used sodium ethylate. A solution of $\mathrm{I} .75 \mathrm{~g}$. of sodium in $50 \mathrm{cc}$. of alcohol was added to a boiling solution of $25 \mathrm{~g}$. of the monobromo compound in $300 \mathrm{cc}$. of the same solvent. The reaction went to completion without further heating. The solution deposited I $8 \mathrm{~g}$. of crystalline product which gave $15 \mathrm{~g}$. of pure cyclopropane derivative after recrystallization from alcohol-a yield of $75 \%$.

Calc. for $\mathrm{C}_{28} \mathrm{H}_{18} \mathrm{O}_{2}$ : C, $84.6 ; \mathrm{H}, 5.6$. Found: $\mathrm{C}, 84.2 ; \mathrm{H}, 6.0$. 
The cyclopropane derivative crystallizes in needles and melts at $116^{\circ}$. It is slightly soluble in ether, moderately soluble in boiling alcohol, cold benzene and chloroform. Its solutions in acetone reduce permanganate only on long standing.

An isomeric cyclopropane derivative was obtained by eliminating bromine from the dibromo compound. A solution of three g. each of the dibromo compound and potassium iodide in $150 \mathrm{cc}$. of alcohol was heated on a steam bath for 4 hours. The liquid, which had turned brown after a few minutes' boiling, was then cooled and freed from iodine by shaking with thiosulfate. On evaporation it deposited a yellow solid which became colorless when recrystallized from alcohol. The melting point of the pure compound was $151^{\circ}$. The same substance was obtained by boiling an alcoholic solution of the dibromo compound with zinc dust for $25 \mathrm{~min}-$ utes, but it was impossible to remove all of the bromine without reducing some of the cyclopropane derivative. The yield therefore was small.

Calc. for $\mathrm{C}_{28} \mathrm{H}_{18} \mathrm{O}_{2}$ : C, 84.6; H, 5.6. Found: $\mathrm{C}, 84.2 ; \mathrm{H}, 5.6$.

The substance is slightly soluble in ether, moderately in boiling alcohol, readily in benzene and chloroform. When recrystallized from alcohol containing $1 \%$ sodium hydroxide it passes quantitatively into the isomer which melts at $116^{\circ}$.

The Monoxime.-The two isomeric cylcopropane diketones give the same mono- and dioxime. For preparing the monoxime a solution of 2.7 g. of sodium hydroxide in $5 \mathrm{cc}$. of water was added to a solution of $5 \mathrm{~g}$. of the cyclopropane derivative and I.I g. of hydroxylamine hydrdthloride in roo cc. of alcohol. The mixture was boiled for three hours, then neutralized with hydrochloric acid. On cooling, it deposited white crystals which after one recrystallization from alcohol melted sharply at $144^{\circ}$. The yield was $82 \%$.

$$
\text { Calc. for } \mathrm{C}_{22} \mathrm{H}_{10} \mathrm{O}_{2}: \mathrm{C}, 80.9 ; \mathrm{H}, 5.6 \text {. Found: } \mathrm{C}, 80.7 ; \mathrm{H}, 5.3 \text {. }
$$

The monoxime is sparingly soluble in ligroin and ether, more readily in boiling alcohol, benzene and choroform.

The Di-oxime.-The di-oxime was made like the monoxime but more than twice the amount of hydroxylamine hydrochloride and potassium hydroxide were used for the same quantity of cyclopropane derivative. The product was purified by recrystallization from alcohol. The yield of pure product was $7 \mathrm{~g} \%$.

Calc. for $\mathrm{C}_{25} \mathrm{H}_{20} \mathrm{~N}_{2} \mathrm{O}_{2}: \mathrm{C}, 77.5 ; \mathrm{H}, 5.7 ; \mathrm{N}, 7.9$. Found: $\mathrm{C}, 77.9 ; \mathrm{H}, 6.0 ; \mathrm{N}, 7.7$.

The di-oxime crystallizes in needles, and melts at $175^{\circ}$. It is sparingly soluble in organic solvents except benzene, chloroform, and boiling alcohol.

Reduction of 1,2-Dibenzoyl-3-phenyl-cylopropane.-In the first experiment the substance was boiled with excess of zinc dust in $80 \%$ acetic 
acid. The sole product was triphenyl-cyclopentane diol, melting at $147^{\circ}$. This result showed that the cyclopropane ring had been opened between the benzoyl groups and a new ring closed, but did not establish the order of these events. The experiment was therefore repeated without the use of acid. A solution of $2 \mathrm{~g}$. of the substance in $60 \mathrm{cc}$. of $85 \%$ alcohol was boiled with excess of zinc dust for an hour. The solution was then filtered and poured into water. This precipitated an oil which soon solidified. After recrystallization from alcohol the solid melted at $85^{\circ}$, and a mixed melting point showed that it was benzal-diacetophenone.

Reaction with Halogen Acids.-In alcoholic solution the cyclopropane derivative is not attacked either by hydrochloric or hydrobromic acid. In glacial acetic acid, hydrobromic acid, in the cold, forms a furane derivative which has bromine in a side chain. Since the cyclopropane derivative is not affected by boiling with glacial acetic acid alone it is evident that the first step consists in addition of hydrobromic acid and that the resulting product, as is usual in the case of I,4-diketones, subsequently loses water and forms the furane derivative.

2,5-Diphenyl-4-( $\alpha$-bromobenzyl)-furane,

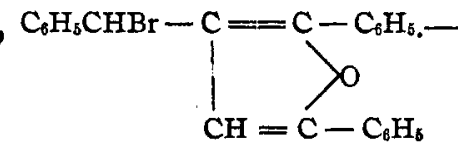

A solution of $5 \mathrm{~g}$. of the cyclopropane derivative in $50 \mathrm{cc}$. of glacial acetic acid was saturated with hydrogen bromide. The solution gradually turned green, and while standing overnight deposited $5.2 \mathrm{~g}$. of a greenish yellow solid. This was purified by recrystallization from glacial acetic acid.

Calc. for $\mathrm{C}_{28} \mathrm{H}_{17} \mathrm{OBr}$ : C, 70.9; $\mathrm{H}, 4.4 ; \mathrm{Br}, 20.5$. Found: $\mathrm{C}, 70.5 ; \mathrm{H}, 3.9 ; \mathrm{Br}, 20.5$.

The bromo compound crystallizes in greenish yellow prisms and melts at $110^{\circ}$. It is sparingly soluble in ether, moderately in ligroin, teadily in benzene and chloroform. It is a reactive substance; the halogen is readily replaced by hydroxyl, acetyl, and other groups, and its solution in acetone reduces permanganate at the ordinary temperature.

2,5-Diphenyl-4-( $\alpha$-acetoxylbenzyl)furane, $\mathrm{C}_{6} \mathrm{H}_{5} \mathrm{CH}-\mathrm{C}==\mathrm{C}-\mathrm{C}_{6} \mathrm{H}_{5}-$ $\mathrm{CH}_{8} \mathrm{OC}-\mathrm{O}$<smiles>CCC1(CC)CCCO1</smiles>

A solution of $3 \mathrm{~g}$. of the bromo compound and $6 \mathrm{~g}$. of potassium acetate in $20 \mathrm{cc}$. of glacial acetic acid, was heated to near the boiling point for half an hour, then cooled and poured into water. This precipitated a white solid, which after purification from alcohol melted at $84^{\circ}$.

Calc. for $\mathrm{C}_{23} \mathrm{H}_{20} \mathrm{O}_{8}: \mathrm{C}, 8 \mathrm{r} .5 ; \mathrm{H}, 5.4$. Found: $\mathrm{C}, 82 . \mathrm{r} ; \mathrm{H}, 5.5$.

The acetate crystallizes in yellow needles. It is moderately soluble in alcohol and in ether, readily in benzene and chloroform. Its solution in acetone reduces permanganate. 
2,5-Diphenyl-4-( $\alpha$-hydroxybenzyl)furane, $\mathrm{C}_{6} \mathrm{H}_{5} \mathrm{CHOHC}==\mathrm{C}-\mathrm{C}_{6} \mathrm{H}_{5}-$<smiles>C=C(CC)C(=C)OC</smiles>

The hydroxyl compound was formed both when the bromo compound was hydrolyzed with sodium alcoholate and when the acetate was hydrolyzed with alcoholic hydrochloric acid. A solution of sodium methylate made by dissolving one g. of sodium in $25 \mathrm{cc}$. of methyl alcohol was added to a hot solution of $5 \mathrm{~g}$. of the bromo compound in $100 \mathrm{cc}$. of alcohol. The mixture, which was not heated further, gradually deposited $+\mathrm{g}$. of the hydroxyl compound, a quantitative yield. A solution of $2 \mathrm{~g}$. of the acetate in $50 \mathrm{cc}$. of alcohol containing $3 \%$ of hydrochloric acid was boiled for 4 hours. On cooling it deposited the same hydroxyl compound which had been obtained in the alkaline hydrolysis.

$$
\text { Calc. for } \mathrm{C}_{24} \mathrm{H}_{18} \mathrm{O}_{2}: \mathrm{C}, 84.7 ; \mathrm{H}, 5.5 \text {. Found: } \mathrm{C}, 84.4 ; \mathrm{H}, 6.0 \text {. }
$$

The substance was purified by recrystallization from alcohol. It crystallizes in needles, melts at $105^{\circ}$, and is moderately soluble in ether and boiling alcohol, readily in chloroform. Its solution in acetone reduces permanganate. Boiling glacial acetic acid converts it into the acetate melting at $84^{\circ}$. Oxidation with potassium permanganate gave benzoic acid and oils, but chromic acid in glacial acetic acid resulted in a crystalline product. For the purpose of oxidation $3 \mathrm{~g}$. of chromic anhydride was added to a cold solution of $5 \mathrm{~g}$. of the hydroxyl compound in glacial acetic acid. As the solution warmed up the temperature was controlled by cooling under the tap. The mixture was allowed to stand overnight, then diluted with roo cc. of water and digested on a steam bath in order to coagulate the oil which was precipitated. The aqueous layer was decanted, the oil washed with water, and dissolved in methyl alcohol. The solution yielded a solid which, after a few recrystallizations from the same solvent, melted at $89^{\circ}$. The yield was $2.4 \mathrm{~g}$.

The analyses of this substance gave variable results until it was discovered that it readily loses water. The loss in weight on drying at $110^{\circ}$ was $4.9 \%$. Analyses of the dried material gave the following results:

Calc. for $\mathrm{C}_{28} \mathrm{H}_{18} \mathrm{O}_{3}: \mathrm{C}, 80.7 ; \mathrm{H}, 5.3$. Found: $\mathrm{C}, 80.7 ; \mathrm{H}, 5.5$.

Calc. for $\mathrm{C}_{23} \mathrm{H}_{20} \mathrm{O}_{4}: \mathrm{H}_{2} \mathrm{O}, 5.0 ; \mathrm{m}$. w. 360 . Found: $\mathrm{H}_{2} \mathrm{O}, 4.7 ; \mathrm{m}$. w. 340 .

The substance to be expected in this oxidation is benzoyl-diphenylfurane.

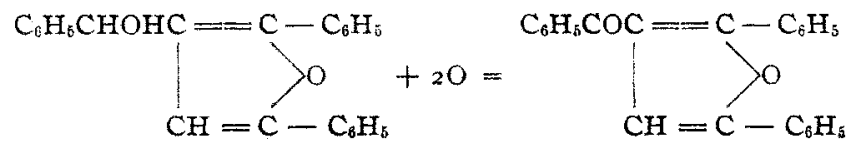

The product actually isolated differs from this by 2 molecules of water. One of these is held very loosely as it is lost when the substance is heated to $110^{\circ}$. The other is removed when the substance is boiled with alco- 
holic potassium hydroxide, hydrochloric acid in methyl alcohol, or acetic anhydride and sodium acetate. As all of these reagents have the power of transforming I,4-diketones into furane derivations, it is possible that the furane ring is opened during the oxidation and that the product is a triketone which crystallizes with one molecule of water.

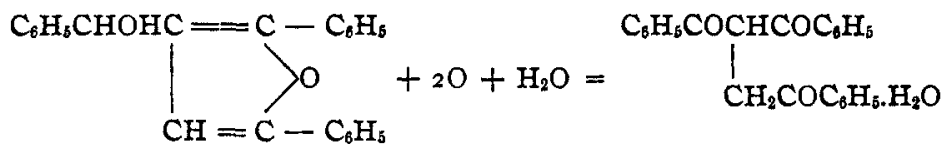

It seems quite as likely, however, that during the process of oxidation the furane derivative combines with two molecules of water and forms a tetrahydro furane derivative. As the purpose of the oxidation was to determine the structure of the hydroxyl compound this matter was not investigated further.

2,5-Diphenyl-4-benzoyl-furane, $\mathrm{C}_{6} \mathrm{H}_{6} \mathrm{COC}=\mathrm{C}-\mathrm{C}_{6} \mathrm{H}_{6}$. $-\mathrm{A}$ solution of<smiles>CCCCCCC</smiles>

$4.5 \mathrm{~g}$. of the oxidation product in $45 \mathrm{cc}$. of methyl alcohol was boiled with $4 \mathrm{~g}$. of potassium hydroxide for 4 hours. A yellow oil separated during the process and increased in amount when the solution was allowed to stand for some time at the ordinary temperature. This was washed and dissolved in methyl alcohol. The solution gave $1.2 \mathrm{~g}$. of yellow needles. The aqueous layer was carefully examined for sodium benzoate, but none was found.

Calc. for $\mathrm{C}_{23} \mathrm{H}_{16} \mathrm{O}_{2}: \mathrm{C}, 85.2 ; \mathrm{H}, 5.0$. Found: $\mathrm{C}, 84.8,84.7 ; \mathrm{H}, 5.0,5.2$.

The same benzoyl derivative was obtained when the oxidation product was boiled with acetic anhydride containing a trace of sodium acetate, and with methyl alcoholic hydrochloric acid. It is moderately soluble in boiling alcohol, readily in ether, benzene and chloroform.

2,5-Diphenyl - 3-bromo-4-benzoyl-furane, $\mathrm{C}_{6} \mathrm{H}_{4} \mathrm{COC}=\mathrm{C}-\mathrm{C}_{6} \mathrm{H}_{6}-$<smiles>CCCC(C)(Br)OC</smiles>

Diphenyl-benzoyl-furane, in chloroform solution, was treated with a very little more than the calculated amount of bromine. The chloroform, on evaporation, left a pale yellow solid. This, after crystallization from alcohol, melted at $120^{\circ}$.

$$
\text { Calc. for } \mathrm{C}_{28} \mathrm{H}_{17} \mathrm{O}_{3}: \mathrm{C}, 65.5 ; \mathrm{H}, 4 \text {.o. Found: } \mathrm{C}, 65.7 ; \mathrm{H}, 3.7 \text {. }
$$

The bromo compound crystallizes in yellow needles. It is moderately soluble in cold alcohol, readily in hot alcohol, ether and chloroform. The bromine is quite unreactive. The substance was boiled in alcoholic solution with potassium acetate for Io hours, with potassium hydroxide for 4 
hours, and with sodium methylate for 3 hours, and in each case recovered unchanged.

The Oxime of 2,5-Diphenyl-4-benzoyl-furane, $\mathrm{C}_{6} \mathrm{H}_{6} \mathrm{C}-\mathrm{C}=\mathrm{C}-\mathrm{C}_{6} \mathrm{H}_{6}$. HON

$\mathrm{CH}=\mathrm{C}-\mathrm{C}_{6} \mathrm{H}_{5}$ -The oxidation product was boiled with methyl alcoholic potassium hydroxide for 4 hours in order to insure complete conversion into diphenylbenzoyl-furane. Hydroxylamine was then added to the solution and the boiling continued for two hours more. Most of the alcohol was distilled off and the residue poured into water and the solution neutralized with hydrochloric acid. The resulting solid was purified by crystallization from alcohol.

$$
\text { Calc. for } \mathrm{C}_{28} \mathrm{H}_{1} ; \mathrm{O}_{2} \mathrm{~N} \text { : C, } 81.4 ; \mathrm{H}, 5.0 \text {. Found: C, 8I.8; H, } 5.4 \text {. }
$$

The oxime crystallizes in rosets of needles and melts at $174^{\circ}$. It is slightly soluble in ether, moderately in boiling alcohol, readily in benzene and chloroform.

2,5-Diphenyl-furane-carboxanilide, $\quad \mathrm{C}_{6} \mathrm{H}_{5} \mathrm{NHCOC}==\mathrm{C}-\mathrm{C}_{6} \mathrm{H}_{5 .}-T_{\mathrm{CH}=\mathrm{C}}>^{-}$

oxime readily undergoes the Beckmann re-arrangement to the corresponding anilide. A suspension of $5 \mathrm{~g}$. of the oxime and $7.5 \mathrm{~g}$. of phosphorus pentachloride in dry ether was allowed to stand at the ordinary temperature overnight. The ether was then distilled off and the residue decomposed with ice water. The solid was washed until free from phosphorus compounds, and recrystallized from alcohol.

$$
\text { Calc. for } \mathrm{C}_{28} \mathrm{H}_{17} \mathrm{O}_{2} \mathrm{~N}: \mathrm{C}, 8 \mathrm{I} .4 ; \mathrm{H}, 5.0 \text {. Found: } \mathrm{C}, 8 \mathrm{r} .4 ; \mathrm{H}, 5 . \mathrm{r} \text {. }
$$

The anilide crystallizes in colorless needles and melts at $187^{\circ}$. It is slightly soluble in ether and alcohol, moderately in hot benzene, readily in chloroform.

2,5-Diphenyl-furane Carboxylic Acid-4, $\mathrm{HO}_{2} \mathrm{C}-\mathrm{C}==\underset{\mathrm{CH}=\mathrm{C}-\mathrm{C}_{6} \mathrm{H}_{6}}{\mathrm{C}}-\mathrm{C}_{6} \mathrm{H}_{5}-\mathrm{A}$

solution of $4 \mathrm{~g}$. of the anilide and $15 \mathrm{~g}$. of potassium hydroxide in 50 cc. of alcohol was boiled for to hours. The alcohol was then distilled off and the residue distilled with steam as long as aniline could be detected in the distillate. This left a solid which was almost completely soluble in $400 \mathrm{cc}$. of water. After filtration to remove a small quantity of resin, acids precipitated a colorless solid, , which was purified by recrystallization from alcohol. It melted at $217^{\circ}$.

Calc. for $\mathrm{C}_{17} \mathrm{H}_{12} \mathrm{O}_{8}: \mathrm{C}, 77.3 ; \mathrm{H}, 4.5$. Found: $\mathrm{C}, 77.0 ; \mathrm{H}, 4.6$.

The acid has both the composition and the melting point of the 2,5diphenyl-furane-carboxylic acid- 3 described by Paal and Lapf, Perkin, 
and Thiele. In order to complete its identification it was distilled with zinc dust. The product was 2,5-diphenyl-furane-identified by a mixed melting point, using a specimen on hand.

Reaction with Grignard Reagents, I,2-Diphenylcarbinyl-3-phenylcyclopropane, $\mathrm{C}_{6} \mathrm{H}_{5} \mathrm{CH}-\mathrm{CHC}\left(\mathrm{C}_{6} \mathrm{H}_{6}\right)_{2} \mathrm{OH}$. - An ethereal solution of phenyl $\mathrm{CHC}\left(\mathrm{C}_{6} \mathrm{H}_{6}\right)_{2} \mathrm{OH}$

magnesium bromide was made from $7.59 \mathrm{~g}$. of magnesium in the usual way. The solution was cooled in a freezing mixture, treated with $20 \mathrm{~g}$. of the cyclopropane derivative, which was added in small quantities as a fine powder. The mixture was allowed to stand at the ordinary temperature for several hours, before it was decomposed with iced acid. The ethereal layer, on evaporation, left a solid imbedded in a pasty oil. Recrystallization from alcohol gave a solid, crystallizing in clusters of fine needles melting at $183^{\circ}$. The yield was $42 \%$.

Calc. for $\mathrm{C}_{35} \mathrm{H}_{30} \mathrm{O}_{2}$ : C, 87.I; H, 6.3. Found: C, 87.3; H, 6.4.

The composition of the product shows that it was formed as a result of the combination of one molecule of cyclopropane derivative and two of phenyl magnesium bromide. In order to determine whether either of the latter had been taken up in the $I, 4$ position, giving an open chained ketone, I.5 g. of the substances was added to a large excess of ethyl magnesium bromide. There was free evolution of ethane. The resulting magnesium derivative, treated in the usual way, yielded only unchanged substance. This, therefore, is not a ketone, but a ditertiary alcohol, showing that the phenyl magnesium bromide had not attacked the ring.

1,2-( $\alpha$-Phenyl- $\alpha$-ethyl-carbinyl)-2-phenyl Cyclopropane, $\mathrm{C}_{6} \mathrm{H}_{6} \mathrm{CH}-\mathrm{CHC}\left(\mathrm{C}_{6} \mathrm{H}_{5}\right)\left(\mathrm{C}_{2} \mathrm{H}_{5}\right) \mathrm{OH}$, was obtained when the cyclopropane $\mathrm{CHC}\left(\mathrm{C}_{6} \mathrm{H}_{6}\right)\left(\mathrm{C}_{2} \mathrm{H}_{6}\right) \mathrm{OH}$

derivative was treated with ethyl magnesium bromide and the product isolated in the usual way. It was purified by recrystallization from ligroin. It melts at $I 29^{\circ}$ and is moderately soluble in ligroin, ether, and alcohol; very soluble in acetone. The yield was $35 \%$.

$$
\text { Calc. for } \mathrm{C}_{27} \mathrm{H}_{80} \mathrm{O}_{2} \text { : C, 83.9; } \mathrm{H}, 7.9 \text {. Found: } \mathrm{C}, 83.5 ; \mathrm{H}, 7.8 \text {. }
$$

Reaction with Phosphorus Pentachloride, I,4-Diphenyl-I,4-dichloro3-benzoyl-butene-4, $\mathrm{C}_{6} \mathrm{H}_{5} \mathrm{CHCl}-\mathrm{CH}\left(\mathrm{COC}_{6} \mathrm{H}_{5}\right) \mathrm{CH}=\mathrm{CClC}_{6} \mathrm{H}_{5}$. - A solution of Io $\mathrm{g}$. of the cyclopropane derivative and $6.4 \mathrm{~g}$. of phosphorus pentachloride in $30 \mathrm{cc}$. of dry benzene was boiled for ro hours, cooled and poured on cracked ice. The benzene layer was separated, washed until free from phosphorus compounds, dried, and evaporated under reduced pressure. It left an oil, which was dissolved in alcohol. The alcoholic solution slowly deposited a solid which after two recrystallizations from the same solvent showed a constant melting point of $122^{\circ}$ 
Calc. for $\mathrm{C}_{23} \mathrm{H}_{18} \mathrm{OCl}_{2} ; \mathrm{C}, 72.5 ; \mathrm{H}, 4.7 ; \mathrm{Cl}, 18.6$. Found: $\mathrm{C}, 72.3 ; \mathrm{H}, 4.8 ; \mathrm{Cl}, 18.7$.

The substance is sparingly soluble in ether, moderately in hot alcohol, readily in benzene and chloroform. It was not affected by boiling with water and it was recovered unchanged after it had been boiled for ro hours with a $3 \%$ solution of hydrochloric acid in methyl alcohol. It is therefore not a ketochloride formed by replacing the oxygen of one of the carbonyl groups with 2 atoms of chlorine.

I,4-Diphenyl-2-benzoyl-4-chloro-butadiene, $\mathrm{C}_{6} \mathrm{H}_{5} \mathrm{CH}=\mathrm{C}\left(\mathrm{COC}_{6} \mathrm{H}_{5}\right)$ $\mathrm{CH}=\mathrm{CClC}_{6} \mathrm{H}_{5}$.- - A solution of $\mathrm{IO} \mathrm{g}$. of the dichloro compound and $30 \mathrm{~g}$. of anhydrous potassium acetate in $150 \mathrm{cc}$. of dry methyl alcohol was boiled for to hours. Most of the alcohol was distilled off, and the residue diluted with water. This precipitated an oil which soon solidified. The solid was thoroughly washed with water and then recrystallized from alcohol.

Calc. for $\mathrm{C}_{28} \mathrm{H}_{17} \mathrm{OCl}: \mathrm{C}, 80.1 ; \mathrm{H}, 4.9$. Found: $\mathrm{C}$, 80;0; $\mathrm{H}, 5.0$.

The substance crystallizes in colorless prisms and melts at $84^{\circ}$. Its solution in acetone reduced permanganate, giving benzoic acid as the only organic product.

I, I,4-Triphenyl-2-benzoyl-4-chloro-butene-3, $\left(\mathrm{C}_{6} \mathrm{H}_{5}\right)_{2} \mathrm{CHCH}\left(\mathrm{COC}_{6} \mathrm{H}_{5}\right)$ $\mathrm{CH}=\mathrm{CClC}_{6} \mathrm{H}_{5}$.- An ethereal solution of phenyl magnesium chloride containing $2 \mathrm{~g}$. of magnesium was prepared in the usual way and cooled in a freezing mixture. To it was added $5 \mathrm{~g}$. of the unsaturated chloroketone in small quantities, and as a finely powdered solid. Each addition produced a yellow color which quickly disappeared again. The mixture was poured into iced acid as soon as all of the substance had been added. The product, isolated in the usual way, and purified by crystallization from alcohol, separated in large, colotless prisms which melted at $140^{\circ}$.

Catc. for $\mathrm{C}_{32} \mathrm{H}_{23} \mathrm{ClO}: \mathrm{C}, 82.4 ; \mathrm{H}, 5.4$. Found: $\mathrm{C}, 82.1 ; \mathrm{H}, 5.7$.

In order to determine the presence or absence of a hydroxyl group, the substance was added to ethyl magnesium bromide. It reacted vigorously, but no evolution of gas accompanied the reaction and no unchanged substance was recovered when the magnesium derivative was acidified. The product is therefore a ketone formed by 1,4-addition, and not a tertiary alcohol such as would be obtained by addition of phenyl magnesium bromide to a carbonyl.

Action of Bromine on the Cyclopropane Derivative.-Bromine reacts with the substance very readily but it is difficult to confine the reaction to the first step. In order to get a crystalline product it was necessary to use small quantities of material. A solution of $2 \mathrm{~g}$. of the substance and $0.33 \mathrm{cc}$. of bromine in $4 \mathrm{cc}$. of chloroform was warmed for a few seconds to start the reaction. As soon as the color of the solution had disappeared, $50 \mathrm{cc}$. of alcohol was added to prevent further change. The 
product was a mixture, but repeated recrystallization from alcohol resulted in a pure substance which melted with decomposition at $129^{\circ}$

$$
\text { Calc. for } \mathrm{C}_{23} \mathrm{H}_{18} \mathrm{O}_{2} \mathrm{Br}_{2}: \mathrm{Br} \text {, 32.9. Found: } \mathrm{Br} \text {, 32.9. }
$$

The substance is isomeric with the $\alpha, \gamma$-dibromo compound obtained by direct bromination of benzal-acetophenone. With potassium iodide it gave the same cyclopropane derivative that was obtained from the $\alpha, \gamma$ dibromo compound, and both substances also gave the same monobromo compound with potassium acetate.

The possible formulas of the addition product are therefore
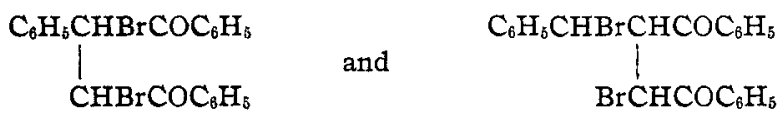

The first formula represents a stereoisomer of the compound, obtained by direct bromination; the second a structural isomer formed by opening the ring between carbon atoms $I$ and 2 . Both the known $\alpha, \gamma$-compound and the substance under consideration first lose hydrogen bromide when treated with any reagent capable of replacing bromine. Since both give the same product when hydrogen bromide is removed, the only method available for distinguishing between them was to transform them into furane derivatives with acid reagents. This was tried with alcoholic hydrogen bromide, and also with acetic anhydride; but both substances gave only oily products.

\section{I,2-Dibenzoyl-2-bromo-3-phenyl-cyclopropane, $\mathrm{C}_{6} \mathrm{H}_{6} \mathrm{CH}-\mathrm{CHCOC}_{6} \mathrm{H}_{5}$ - $\mathrm{BrCCOC}_{8} \mathrm{H}_{5}$}

A solution of $\mathrm{IO} \mathrm{g}$. of the $\alpha, \gamma$-dibromo compound in $200 \mathrm{cc}_{\text {, }}$ of absolute alcohol was treated with $2.2 \mathrm{~g}$. of potassium acetate and $5 \mathrm{~g}$. of precipitated calcium carbonate, and the whole boiled for 4 hours. The mixture was then poured into water. This precipitated a solid which was recrystallized from alcohol. The yield was $4 \mathrm{~g}$., or $47 \%$.

Calc. for $\mathrm{C}_{23} \mathrm{H}_{17} \mathrm{O}_{2} \mathrm{Br}: \mathrm{C}, 68 . \mathrm{I} ; \mathrm{H}, 4.2 ; \mathrm{Br}$, I9.7. Found: $\mathrm{C}, 68 . \mathrm{I} ; \mathrm{H}, 4.4 ; \mathrm{Br}, 19.7$.

The substance crystallizes in needles and melts at $122^{\circ}$. It is sparingly soluble in ether and cold alcohol, moderately in boiling alcohol. Our attempts to remove another molecule of hydrogen bromide from this substance and thus get a cyclopropene derivative were unsuccessful. Alkalies gave only oily products and potassium acetate replaced bromine with acetyl.

I,2-Dibenzoyl-2-acetoxy-3-phenyl-cyclopropane, $\mathrm{C}_{6} \mathrm{H}_{5} \mathrm{CH}-\mathrm{CHCOC}_{6} \mathrm{H}_{5}$. $\mathrm{CH}_{3} \mathrm{COO}-\mathrm{C}-\mathrm{COC}_{6} \mathrm{H}_{5}$

-A solution of ro g. of dibromo compound in $200 \mathrm{cc}$. of absolute alcohol was treated with ro $\mathrm{g}$. of fused potassium acetate and $5 \mathrm{~g}$. of precipitated calcium carbonate. The mixture was boiled for 4 hours, then filtered while 
hot and allowed to crystallize. The product was purified by recrystallization from alcohol.

$$
\text { Calc, for } \mathrm{C}_{25} \mathrm{H}_{20} \mathrm{O}_{4}: \mathrm{C}, 78.1 ; \mathrm{H}, 5.2 \text {. Found: } \mathrm{C}, 77.7 ; \mathrm{H}, 5.9 \text {. }
$$

The substance melts at $159^{\circ}$. Its solution in acetone very slowly reduces permanganate. An attempt to get the corresponding hydroxyl compound failed; alkalies led to unmanageable oils while acids resulted in the formation of a furane derivative.

2-Benzoyl-3,5-diphenyl-furane, $\quad \mathrm{CH}=\mathrm{C}-\mathrm{C}_{6} \mathrm{H}_{5}$,-Twelve cc. of<smiles>CC=CC(=O)CCC</smiles>

conc. hydrochloric acid was added to a solution of ro g. of the acetoxy compound in $8 \mathrm{o} \mathrm{cc}$. of alcohol. The mixture was boiled for 4 hours. On cooling it deposited a pink colored solid in fine plates. The pink color disappeared on recrystallization from alcohol, which yielded colorless plates melting at $118^{\circ}$.

Calc. for $\mathrm{C}_{23} \mathrm{H}_{16} \mathrm{O}_{2}: \mathrm{C}, 85.2 ; \mathrm{H}, 5.1 ; \mathrm{m}$. w. 324. Found: $\mathrm{C}, 85.0 ; \mathrm{H}, 4.9 ;$ m. w. 329.

The furane derivative is sparingly soluble in alcohol, readily in benzene and chloroform. It has one hydrogen that is replaceable by bromine. With excess of hydroxylamine it forms only a monoxime even on prolonged boiling. It therefore contains but one carbonyl group-proof that it is a furane derivative and not the isomeric cyclopropane. Nascent hydrogen attacks the benzoyl group and reduces it to a benzyl group without either opening or saturating the ring.

2-Benzoyl-4-bromo-3,5-diphenyl-furane, $\mathrm{BrC}=\mathrm{C}-\mathrm{C}_{6} \mathrm{H}_{5} \quad$.- A solu-<smiles>CCCC(C)C(=O)OCC</smiles>

tion containing $5 \mathrm{~g}$. of the furane derivative and $2.5 \mathrm{~g}$. of bromine was gently warmed until the color disappeared. The solution on evaporation left the bromo compound as a colorless solid which, after recrystallization from alcohol, melted at $110^{\circ}$. The bromine is completely inactive, not a trace of silver bromide being formed on protracted boiling with silver acetate.

Calc. for $\mathrm{C}_{23} \mathrm{H}_{16} \mathrm{BrO}: \mathrm{C}, 68.4 ; \mathrm{H}, 3.7 ; \mathrm{Br}$, 29.8. Found: $\mathrm{C}, 68.1 ; \mathrm{H}, 3.9 ; \mathrm{Br}, 19.9$.

2-Benzyl-3,5-diphenyl-furane, $\mathrm{HC}=\mathrm{C}-\mathrm{C}_{8} \mathrm{H}_{0}$.-A solution of $4 \mathrm{~g}$.

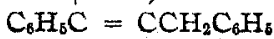

of benzoyl-diphenyl-furane in $50 \mathrm{cc}$. of glacial acetic acid was heated on a steam bath and treated with $5 \mathrm{~g}$. of zinc dust in small portions. A yellow solid separated during the process and a viscous yellow oil was precipitated when the solution was poured into water. Both the solid and the oil were dissolved in boiling acetone. On addition of alcohol to the hot 
solution, the product separated in bright yellow needles melting at $193^{\circ}$ The mother liquors contained unchanged substance.

$$
\text { Calc. for } \mathrm{C}_{28} \mathrm{H}_{18} \mathrm{O}: \mathrm{C}, 89.3 ; \mathrm{H}, 5.8 \text {. Found: } \mathrm{C}, 89.3 ; \mathrm{H}, 6 . \mathrm{I} \text {. }
$$

The substance is very sparingly soluble in all solvents except hot acetone and hot chloroform.

The Oxime of benzoyl-diphenyl-furane was made by boiling an alcoholic solution of $4 \mathrm{~g}$. of the ketone, $4 \mathrm{~g}$. of hydroxylamine hydrochloride, and 5 g. of potassium hydroxide for 4 hours. Most of the alcohol was distilled off and the residue poured into water. The resulting solid, after recrystallization from ethyl alcohol, melted at $\mathrm{I}_{52^{\circ}}$.

Calc. for $\mathrm{C}_{23} \mathrm{H}_{17} \mathrm{O}_{2} \mathrm{~N}$ : C, 81.4; H, 5. Found: $\mathrm{C}, 8 \mathrm{r} .1 ; \mathrm{H}, 5.2$.

The oxime crystallizes in needles. It is insoluble in water, moderately soluble in alcohol, readily in ether.

3,5-Diphenyl-furane Carboxanilide-2,

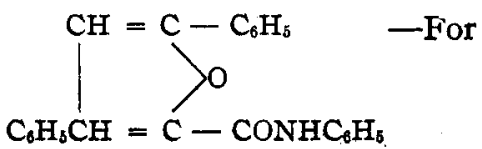

the purpose of rearranging the oxime an ethereal solution of the substance was allowed to stand in contact with excess of phosphorus pentachloride for several hours and then cautiously decomposed with ice water. The resulting oil, after thorough washing with water, was dissolved in alcohol. It separated in colorless needles melting at $143^{\circ}$.

Calc. for $\mathrm{C}_{28} \mathrm{H}_{17} \mathrm{O}_{2} \mathrm{~N}$ : C, 8I.4; H, 5.0. Found: C, 8I.I; H, 5.2.

3,5-Diphenyl-furane Carboxylic Acid-2, $\quad \mathrm{CH}=\mathrm{C}-\mathrm{C}_{6} \mathrm{H}_{6}$. -The ani-

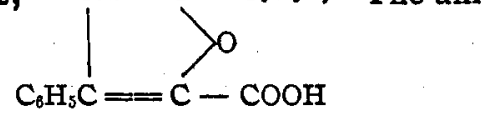

lide was hydrolyzed by prolonged boiling with alcoholic potassium hydroxide, and the resulting acid recrystallized from alcohol.

Calc. for $\mathrm{C}_{17} \mathrm{H}_{12} \mathrm{O}_{8}: \mathrm{C}, 77.3 ; \mathrm{H}, 4.5$. Found: $\mathrm{C}, 77.7 ; \mathrm{H}, 4.7$.

The acid melted with decomposition, at $194^{\circ}$. When heated with zinc dust it gave 3,5-diphenyl-furane which distilled without decomposition, crystallized in irridescent plates, that melted at $109^{\circ}$, gave a blue fluorescent solution in conc. sulfuric acid, and was identical in every way with the $\alpha, \gamma$-diphenyl-furane described by Engler and Dengler. ${ }^{1}$

Cambridge, Mass.

2 Ber., 26, 1447 (1893) 